\title{
Assessing directionality in context
}

\author{
Stefanie Dose \\ Department of Linguistics, University of Johannesburg, South Africa \\ E-mail: sdose@uj.ac.za
}

\begin{abstract}
The directionality debate in interpreting revolves around the question of whether and how (simultaneous) interpreters' performance differs when working from a second and into a first language compared to interpreting from a first and into a second language. Interpreting into a second language remains a controversial practice that has been dubbed "retour interpreting", "active interpreting", "service translation", or "inverse translation" (Pavlovič 2007), terms that reflect the traditionally critical attitudes towards the practice. While many scholars argue in favour of either one of the two interpreting directions, often rejecting the opposite direction as producing interpreting of inferior quality, more recent research suggests that other, extralinguistic factors may have interpreting direction-specific effects on an interpreter's performance (Gile 2005), which may explain contradictory findings in the literature. The pilot study reported on in this article examines the interaction between one such extralinguistic factor, namely interpreters' familiarity with the context of the speech to be interpreted, and interpreting direction by analysing the examination performances of eight interpreters following a postgraduate simultaneous interpreting course. The course participants were recorded interpreting speeches into both their first and second languages on familiar as well as unfamiliar topics; their individual performances were then compared on the basis of examiners' assessments of the individual renditions. The results provide support for the notion that interpreters' familiarity with the context of a speech does indeed have a direction-specific effect on interpreting quality and provides more consistent benefits for second-language interpreting than for first-language interpreting.
\end{abstract}

Keywords: directionality, familiarity with the topic, interpreter performance

\section{Introduction}

The directionality debate in interpreting revolves around the question of whether and how interpreters' performance differs when working from a second and into a first language (firstlanguage interpreting) compared to interpreting from a first and into a second language (secondlanguage interpreting). Traditionally, conference interpreters have worked mainly into their first language or "A" language. The Directorate General for Interpretation, the European Commission's interpreting service, confirms that this remains the case in many institutions: 
Normally, interpreters work into their mother tongue. Some interpreters know a second language well enough to be able to work into that language (second active or "B-language") from their mother tongue. This is called "retour" interpreting. The French word for return is universally employed. A small number of interpreters know their second active language so well that they are able to interpret into that language from all the languages in their language combination (Directorate General for Interpretation 2013).

In support of first-language interpreting as the exclusive interpreting direction, many practising interpreters and interpreter trainers in Western Europe have argued that interpreters can only produce a target language product of linguistically and idiomatically impeccable quality when working exclusively into their first language (Seleskovitch 1978). Harris (1989:116) goes so far as to suggest that this preference for first-language interpreting can be considered a norm amongst Western European interpreting schools. This belief in the superiority of first-language interpreting follows from the assumption that an interpreter will always have better comprehension than production skills in a second language and that linguistically faultless target language production, particularly under conditions of stress, can only be achieved in a native language.

However, in South Africa, as in many countries worldwide, market dictates have begun influencing the working conditions of interpreters, who are increasingly being called upon to interpret into their second language as well as into their first language as a matter of course. As most conferences in South Africa are conducted mainly in English, necessitating interpreting into the African languages, Afrikaans, and/or European languages, interpreters with two working languages (one active native language and one active non-native language, typically English) are usually recruited for these assignments. These interpreters are then also routinely required to work into their active non-native languages.

Supporters of second-language interpreting have put forward a number of arguments in favour of this practice. Denissenko (1989), for example, suggests that only second-language interpreting, where the interpreter receives the source language input in a native language, guarantees perfect comprehension of the message, and hence higher accuracy and completeness of the interpreted rendition. The validity of this argument has in turn been contested by proponents of first-language interpreting who believe that while it is not possible to acquire perfect production skills in a non-native language, interpreters do possess perfect comprehension skills in their second language, which guarantees accuracy and completeness during first-language interpreting, too. Furthermore, Viaggio (1991) argues that receiving the source language input in a native language does not necessarily result in better comprehension of the message or in improved accuracy and completeness of the interpreted rendition. This, Viaggio (1991) argues, is because a higher level of linguistic understanding of the source speech makes it more difficult for interpreters to detach themselves from the linguistic form of the message, resulting in lower quality of the target language output.

A second argument in favour of second-language interpreting involves Denissenko's (1989) suggestion that first-language interpreting can have detrimental effects on target language production, as the choice between many available target language phrases involves an additional effort for the interpreter. Lastly, Kalina (2005) argues from a listener's perspective 
that the presumably linguistically simpler target language rendition produced during secondlanguage interpreting may in fact be easier to follow, especially for non-native listeners.

The above theoretical arguments have tended to support one interpreting direction as the ideal one, often condemning the opposite direction as producing interpreting of inferior quality. However, a few remarks by practising interpreters suggest that there is no definite, clear-cut answer to the question of the preferable interpreting direction, as there are numerous extralinguistic factors that may determine whether and when any one interpreting direction is appropriate or not (Lim 2005; Chang 2005). Little research has been conducted to confirm or disprove these intuitive statements and to determine to what extent such extralinguistic factors may indeed interact with interpreting direction. The present study therefore intends to shed some light on the possible interaction between two independent variables, namely interpreting direction and familiarity with the context of the speech to be interpreted. The dependent variable is the quality of interpreters' output in terms of content and language use.

\section{Background}

\subsection{Directionality in interpreting}

A number of scholars have set out to determine the ideal interpreting direction empirically. These studies approach the issue of directionality from various angles, including analyses of interpreters' preferences (e.g. Donovan 2004; Pavlovič 2007), listeners' attitudes (e.g. Kurz 1993; Donovan 2004), the cognitive load experienced by interpreters in each interpreting direction (e.g. Kurz 1994; Hyönä et al. 1995), features of the interpreters' output (e.g. Chang 2005; Tommola \& Laakso 1997; Tommola \& Helevä 1998), and differences in strategies used during first- and second-language interpreting (e.g. Bartłomiejczyk 2006; Gumul 2006).

In some of the above areas of investigation, various researchers reach corresponding results. For example, studies of listeners' attitudes suggest that listeners are largely unconcerned about second-language interpreting (Donovan 2002, 2004; Kurz 1993; Gile 1990) and that they consider other factors, such as interpreters' familiarity with the subject matter of the speech, to be more important. (It should be noted that respondents may not always be in a position to accurately assess certain aspects of interpreting performance such as accuracy or completeness. Hence, they may not be equipped to judge the effect of interpreting direction on interpreters' performance.)

However, results regarding many other aspects of interpreting direction remain inconclusive. For example, according to some surveys, interpreters themselves appear to favour first-language interpreting (Donovan 2002, 2004; Bartłomiejczyk 2004; Lim 2005; Chang 2005), whereas other surveys suggest that interpreters are indifferent towards interpreting direction (Al-Salman \& Al-Khanji 2002; Lim 2005; Pavlovič 2007).

Studies analysing interpreters' target language output usually distinguish between the two main features around which traditional theoretical arguments revolve, namely the quality of the interpreted product's language (grammar, idiom, vocabulary) and the content of the interpreter's output (accuracy, completeness). While most empirical studies concur that language quality is higher during first-language interpreting (Chang 2005; Darò et al. 1996), findings regarding the content accuracy of the interpreter's output are conflicting. Some authors 
find that accuracy is higher during second- than during first-language interpreting (Tommola \& Helevä 1998), a finding that is in line with the arguments of theorists who are in support of second-language interpreting. Sometimes, interpreters achieve similar accuracy during firstand second-language interpreting (Tommola \& Laakso 1997), and sometimes interpreters produce more accurate output during first-language interpreting (Chang 2005).

\subsection{Other factors interacting with directionality}

A possible explanation for these contradictory findings is that, as suggested by practising interpreters, other variables have interacted with directionality to affect interpreters' performances during first- and second-language interpreting in the above studies, possibly offsetting any assumed effects of interpreting direction. Gile (2005:17) too explains that "[i]t is possible, and even plausible, that the effects of language mastery are smaller, and sometimes much smaller, than the effects of other variables".

Some of the above studies point towards a number of variables that may plausibly interact with directionality. These variables, which are discussed in more detail below, include the listeners' linguistic backgrounds, the interpreter's level of expertise, the specific languages from and into which interpreting takes place, interpreters' attitudes towards first- and second-language interpreting, and interpreters' familiarity with the context of the speech to be interpreted.

Regarding the linguistic background of the listeners, Gile (1990) points out that speakers of some languages may simply be more lenient in their assessment of interpreters than others. The anglophone respondents in his study are less critical in their assessment of interpreting quality than are those respondents that belong to francophone language communities.

Studies on the quality of interpreters' output indicate a possible influence of interpreters' varying levels of expertise on their performance in different interpreting directions, too. The participants in many of the studies that point towards higher or similar quality during secondlanguage interpreting are trainee interpreters rather than professionals (Tommola \& Helevä 1998; Tommola \& Laakso 1997). Barik (1994) observes in his study that trainees perform better when interpreting into their second than into their first language, which is not the case for professional interpreters. Bartłomiejczyk (2004) finds, furthermore, that trainee interpreters usually have more confidence in their second-language interpreting skills than professional interpreters do.

Certain particularities of a specific language combination may also affect interpreters' performances in different interpreting directions. Al-Salman and Al-Khanji (2002), for example, argue that Arabic poses particular problems as a target language even to native Arabic speakers due to the differences between the colloquial and formal registers of the language. Kurz and Färber (2003) find that German/English interpreters use anticipation more frequently and more successfully during second-language interpreting. This finding could result from the general requirements of interpreting from a subject-object-verb language into a subject-verbobject language. It may thus be unrelated to the question of interpreters' native and non-native languages.

Interpreters' preferences regarding interpreting direction show that a country's dominant attitude towards second-language interpreting, as well as the status of interpreters' working 
languages, tends to influence interpreters' opinions on second-language interpreting. It is noteworthy that those surveys in which interpreters are found to prefer first-language interpreting rely mainly on interpreters from Western European interpreting schools or members of the International Association of Conference Interpreters (AIIC) as respondents (Donovan 2002, 2004; Bartłomiejczyk 2004; Chang 2005). Those studies in which interpreters are found to be indifferent towards interpreting direction work with languages such as Arabic (Al-Salman \& Al-Khanji 2002), Korean (Lim 2005), and Croatian (Pavlovič 2007). Furthermore, in most cases, respondents do not categorically reject or support second-language interpreting, but rather suggest that the amount of training received in a specific interpreting direction (Donovan 2004) as well as an interpreter's mastery of the second language (Bartłomiejczyk 2004) and the context of the source language speech (Chang 2005) must be considered when deciding whether second-language interpreting is acceptable.

Finally, clients as well as practising interpreters maintain that interpreters' familiarity with the context of the speech to be interpreted may have a sometimes overriding effect on their performance in different interpreting directions (Donovan 2002; Chang 2005; Lim 2005), possibly compensating for the linguistic shortcomings of either of the two interpreting directions. Gile (1993:71) concurs that "the better the extra-linguistic knowledge, the less knowledge of the language is required to reach the same level of comprehension", as long as some minimum level of both linguistic and extralinguistic knowledge is present. This extralinguistic variable is discussed in more detail in the following section.

\subsection{Familiarity with the context}

While there is little research about the interaction between interpreters' familiarity with the context and first- and second-language interpreting, respectively, some authors provide empirical evidence in support of the benefits of context familiarity as such on interpreter performance. Dose (2014), for example, demonstrates that interpreters' transfer of cohesive links from the source into the target language is more successful (i.e. resulting in cohesive relations in the target language speech that resemble those in the source language speech) when interpreters are familiar with the topic of the speech to be interpreted. Al-Salman and Al-Khanji (2002) find that interpreters apply more successful interpreting strategies when they are familiar with the context of the source language speech; Vuorikoski (2004:236) finds that renditions by interpreters who are unfamiliar with the context of the source language speech include more omissions and errors than those by interpreters who are familiar with the context.

Although context familiarity per se may positively affect interpreting performance, it is not clear to what extent it can compensate for the comprehension and/or production gaps that interpreters presumably experience when they interpret in different directions. For example, according to some interpreting scholars, either the presumably limited production skills during second-language interpreting or the presumably limited comprehension levels during firstlanguage interpreting (or possibly both) may benefit from interpreters' familiarity with the context. Setton (2004:15) notes the benefits of "acquiring the local and specialised contexts" relating to the event to be interpreted and argues that a greater understanding of such contexts may to some extent compensate for a gap in second-language production proficiency. Gile (2009:83) makes a similar point regarding the interpreter's comprehension of a non-native source language when he states that "it may be possible to achieve a relatively high level of 
comprehension even with a relatively low level of linguistic knowledge provided the level of extralinguistic knowledge is high and vice versa".

However, there is as yet no evidence indicating whether interpreters' familiarity with the context of the speech to be interpreted indeed has any interpreting direction-specific effect on the quality of the interpreter's output. This article suggests that interpreters' context familiarity may have a different effect on second-language interpreting than on first-language interpreting. Assessments of participants' examination performances by two professional interpreter trainers serve as data.

\section{Methodology}

This study analyses the effect that interpreters' familiarity with the context of the speech to be interpreted has on their performances in the two interpreting directions. The analysis examines experienced interpreter trainers' assessments of eight interpreters' performances during a simultaneous interpreting examination based on a standardised rubric. It presents support for the notion that interpreters' familiarity with the context has an interpreting direction-specific effect on these interpreters' performance. The following section summarises information relating to the participating interpreters as well as the data collection process.

\subsection{Participants}

Eight interpreters who had participated in the eight-week postgraduate short course Introduction to Conference Interpreting ${ }^{11}$ at the Wits Language School, University of the Witwatersrand in September 2012 were assessed by two professional interpreter trainers (not including the author) during the practical examination following the course. The course consisted of a six-week online component and a subsequent two-week masterclass and was conducted by an AIIC interpreter trainer.

The linguistic and extralinguistic profiles of the participating interpreters were established during the duration of the course by means of interviews based on the Language Experience and Proficiency Questionnaire developed by Marian, Blumenfeld, and Kaushanskaya (2007). Brief profiles of each participating interpreter are provided in Table 1 below. All eight participants are able to interpret in both interpreting directions, i.e. from English into Afrikaans and from Afrikaans into English (participants A1m, A2m, and A3f); from English into French and from French into English (participants F1m, F2m, F3m, and F4f); and from English into German and from German into English (participant G1f).

\footnotetext{
${ }^{1}$ The name of the course has since changed to Conference Interpreting Skills.
} 
Table 1: Participants' language and extralinguistic backgrounds (from Dose 2014)

\begin{tabular}{|l|l|l|l|l|l|}
\hline Interpreter & L1 & L2 & $\begin{array}{l}\text { Interpreting } \\
\text { experience }\end{array}$ & $\begin{array}{l}\text { Other work experience / } \\
\text { studies }\end{array}$ & $\begin{array}{l}\text { Regularly } \\
\text { interprets }\end{array}$ \\
\hline A1m & Afr & Eng & Yes, mainly into L2 & Law & $\begin{array}{l}\text { Law, sports, } \\
\text { engineering }\end{array}$ \\
\hline A2m & Afr & Eng & $\begin{array}{l}\text { Yes, in both } \\
\text { directions }\end{array}$ & Education & $\begin{array}{l}\text { Physiology, } \\
\text { pharmacy, } \\
\text { economics }\end{array}$ \\
\hline A3f & Afr & Eng & $\begin{array}{l}\text { Mainly training, } \\
\text { both directions }\end{array}$ & Translation & - - - \\
\hline F1m & Fr & Eng & $\begin{array}{l}\text { Yes, in both } \\
\text { directions }\end{array}$ & Business administration & Agriculture \\
\hline F2m & Fr & Eng & $\begin{array}{l}\text { Yes, in both } \\
\text { directions }\end{array}$ & Law, marketing & Politics \\
\hline F3m & Fr & Eng & $\begin{array}{l}\text { Yes, in both } \\
\text { directions }\end{array}$ & - - - & Health, policy \\
\hline F4f & Fr & Eng & $\begin{array}{l}\text { Mainly training, } \\
\text { both directions }\end{array}$ & $\begin{array}{l}\text { Psychology, journalism, } \\
\text { translation }\end{array}$ & - - \\
\hline G1f & Ger & Eng & $\begin{array}{l}\text { Yes, mainly into L2 } \\
\text { Translation }\end{array}$ & $\begin{array}{l}\text { Engineering, } \\
\text { pharmacy, } \\
\text { economics }\end{array}$ \\
\hline
\end{tabular}

\subsection{Interpreting tasks}

Setton (2004) divides the context from which an interpreter's performance may benefit into two types: the "specialised context" refers to the topic or subject matter discussed in the speech, and the "local context" refers to the setting, genre, participants, and aims of the event. This article focuses on the interaction between the specialised context, i.e. interpreters' familiarity with the topic or subject matter discussed in the speech, and interpreting direction. There are therefore two independent variables, namely interpreting direction and context familiarity. Each independent variable consists of two levels: first- and second-language interpreting for interpreting direction, and familiar and unfamiliar subjects for context familiarity. The dependent variable is the quality of the interpreters' output as assessed by the two examiners.

In order to obtain interpreting performances for the two independent variables and each of their two levels, all participants were assessed on their simultaneous interpretations of four different source language speeches. That is, they performed first- and second-language interpreting of speeches representing a familiar and an unfamiliar topic each:

First-language interpreting

Second-language interpreting $\}$ of a speech on a familiar topic

First-language interpreting

Second-language interpreting $\}$ of a speech on an unfamiliar topic

The familiar and unfamiliar source language speeches dealt with the following topics: 
Table 2: Topics of familiar and unfamiliar speeches in the respective source languages

\begin{tabular}{|l|l|l|}
\hline & Familiar topic & Unfamiliar topic \\
\hline Afrikaans & The fall of the Berlin Wall & Religious signage on food packaging \\
\hline English & $\begin{array}{l}\text { Economic development and } \\
\text { partnerships in Africa }\end{array}$ & Human evolution \\
\hline French & Women's rights & The physical properties of the egg shell \\
\hline German & Civil aviation & Self-steering cars \\
\hline
\end{tabular}

The speeches practised during the preceding two-week masterclass mainly focused on the 'familiar' topics on the left-hand side of the table, resulting in interpreters' increased familiarity with these topics. The 'unfamiliar' topics on the right-hand side of the table were not practised during the course, and the interviews with the participating interpreters confirmed that they had not gained any extensive familiarity with such topics through interpreting experience, formal study or personal interests.

\subsection{Shortcomings of source speeches}

All speeches are comparable in length, i.e. approximately ten minutes long. Furthermore, although the speeches are not all exactly equal in terms of source speech input rate, all except the Afrikaans source language speeches can be classified as "slow" according to Sandrelli and Bendazzoli's (2005:4) categorisation of input rates in simultaneous interpreting. Therefore, these speeches are considered to present the interpreters with similar input rates. The Afrikaans source speeches both fall into the "medium" input rate category. This means that input rate constitutes a confounding variable for participants $\mathrm{A} 1 \mathrm{~m}, \mathrm{~A} 2 \mathrm{~m}$, and $\mathrm{A} 3 \mathrm{f}$, for whom the source speech used during second-language interpreting may be considered more difficult in terms of input rate. This fact may be offset to some extent by the fact that lexical density $\left(\mathrm{L}_{\mathrm{D}}\right)$ is lower for the two Afrikaans speeches than for the two English speeches. Lexical density is also lower for the two French source speeches than it is for the two English source speeches. This makes the English source speeches used during first-language interpreting more difficult in terms of lexical density than the French source speeches used during second-language interpreting.

As far as type/token ratio (TTR) is concerned, there is little variation between the Afrikaans, English, and French source speeches; however, the type/token ratio is higher for the (familiar and unfamiliar) German speeches (48.3 and 49.6 respectively) than for the (familiar and unfamiliar) English speeches (43.2 and 43.4 respectively), possibly making second-language interpreting the more difficult direction for this language combination. For the other language combinations, the differences are less severe and therefore less likely to constitute a confounding variable. Table 3 below summarises the input rate and type/token ratio for all source speeches used during the examination.

Input rate, lexical density, and type/token ratio could unfortunately not be controlled for in the present small-scale study, as the source speeches were selected by the examiners without the researcher's involvement. It is possible that differences in input rate, lexical density, and type/token ratio of the individual source speeches may have affected interpreter performance in some cases. These cases will be pointed out in the data analysis sections below. 
Table 3: Source speech characteristics

\begin{tabular}{|c|c|c|}
\hline & Familiar topic & Unfamiliar topic \\
\hline Afrikaans & 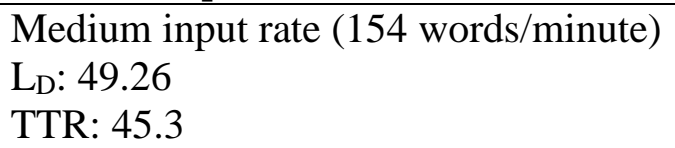 & $\begin{array}{l}\text { Medium input rate (139 words/minute) } \\
\text { LD: } 46.36 \\
\text { TTR: } 43.0\end{array}$ \\
\hline English & 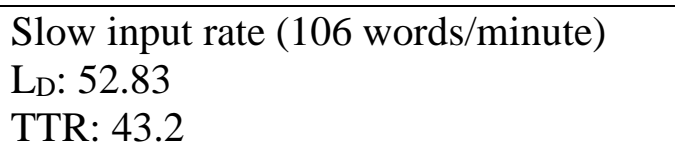 & $\begin{array}{l}\text { Slow input rate (101 words/minute) } \\
\text { LD: } 54.83 \\
\text { TTR: } 43.4\end{array}$ \\
\hline French & $\begin{array}{l}\text { Slow input rate (97 words/minute) } \\
\text { LD: } \text { (7.11 } \\
\text { TTR: } 45.3\end{array}$ & 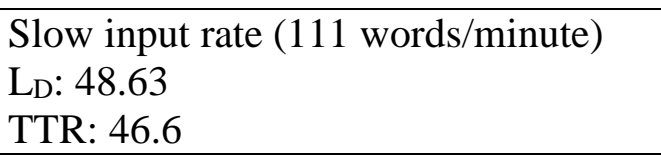 \\
\hline German & 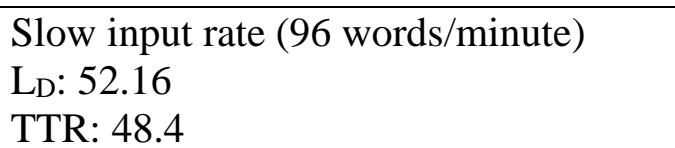 & 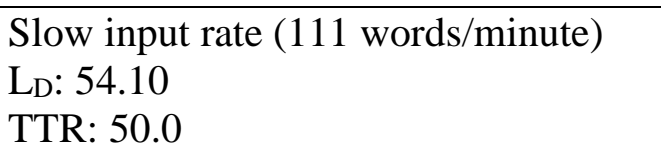 \\
\hline
\end{tabular}

\subsection{Measuring instrument}

The interpreting performances of all eight participants were assessed immediately after each performance by the same two examiners, who are both highly experienced conference interpreters as well as interpreter trainers, and not including the author of the present study, as mentioned above. Marks were allocated according to a standardised rubric consisting of the following categories, with a possible total of 50 marks:

\section{Content (20 marks)}

- Faithfulness to overall message (1-10)

- Accuracy and completeness (1-10)

Language (10 marks)

- Vocabulary and diction (1-5)

- Grammar, coherence, and register (1-5)

\section{Technique (20 marks)}

- Fluency of delivery (1-5)

- Analysis (1-5)

- Use of coping strategies (1-5)

- Poise, eye contact, and voice projection (1-5)

Each examiner scored each interpreting performance individually according to the above rubric. This was followed by a discussion between the two examiners after the interpreting performance to arrive at a single consensus mark. Although the examiners were not given access to the questionnaire or interview results that were used to assess the participants' linguistic backgrounds, they could make assumptions about the participants' mother tongues based on their accents and names.

\section{Data analysis}

This section examines the marks awarded to the participating interpreters for their renditions of the four speeches that they interpreted during the exam. The analysis of the assessments of the interpreted renditions focuses on the "Language" and "Content" categories of the assessment 
rubric described above, as these two categories represent the two factors around which proponents of first- and second-language interpreting have constructed their main arguments. For the purposes of the analysis below, the total marks that were awarded to interpreters for the "Language" category and the "Content" category were converted to percentages. Only the total marks awarded for these two categories were considered, and the marks given for the subcategories under both "Language" and "Content" were not analysed individually. As the sample of interpreters was too small to allow for statistical testing, a level of significance of 5\% was chosen. This means that a mark that differs by at least $5 \%$ from another mark is considered to constitute a difference in interpreting performance. Marks that differ by less than $5 \%$ are considered to indicate similar interpreting performances.

Below, the effect of interpreting direction per se on the language and content of the interpreters' output is analysed. In section 4.1, the marks that interpreters obtained in these two categories for first-language interpreting (of both the familiar and the unfamiliar speeches combined) are compared to the marks obtained for second-language interpreting (of both the familiar and the unfamiliar speeches combined). Section 4.2 analyses the effect of interpreters' context familiarity on the language and content of the interpreters' output by comparing the marks awarded in these two categories for interpreting the familiar speeches (in both interpreting directions combined) and the unfamiliar speeches (in both interpreting directions combined). Lastly, section 4.3 examines whether, according to the examiners' assessments of the content and language of the interpreters' output, context familiarity has an interpreting directionspecific effect on the interpreters' performance. This is done by examining the marks awarded to the interpreters for each of the four speeches individually.

\subsection{Interpreting direction}

\subsubsection{Language}

Comparing participants' language marks (consisting of the individual categories vocabulary and diction and grammar, coherence, and register) awarded for the two (familiar and unfamiliar) speeches interpreted into their first language to the language marks awarded for the two (familiar and unfamiliar) speeches interpreted into their second language indicates that the majority of interpreters perform better during first-language interpreting as far as the language criterion is concerned. As Figure 1 indicates, seven of the eight interpreters were awarded higher language marks in this interpreting direction, and only one interpreter (G1f) - who has spent an extended period of time living outside of a country in which her native language is spoken - was awarded the same language mark in both interpreting directions. None of the participants was awarded a higher language mark for second-language interpreting. Figure 1 below presents the marks each individual participant was awarded for the first- and secondlanguage renditions, showing that almost all participants perform better in first-language interpreting. Although the difference in marks awarded is quite small at only $5 \%$ in the case of F4f, the difference ranges from 10-20\% for the other interpreters. This finding suggests that language quality is indeed higher during first-language interpreting.

It must be pointed out that $\mathrm{A} 1 \mathrm{~m}, \mathrm{~A} 2 \mathrm{~m}$, and $\mathrm{A} 3 \mathrm{f}$ 's better performances during first-language interpreting may have been affected by the fact that the input rate of the speech to be interpreted into the participants' first language was slow, whereas the input rate for the speech to be interpreted into the participants' second language was medium. However, for the French and German participants, input rates were comparable and the differences in marks cannot be 
attributed to different input rates. Furthermore, the German interpreter performed equally well during first- and second-language interpreting, despite the fact that second-language interpreting presented her with a source speech with a higher type/token ratio.

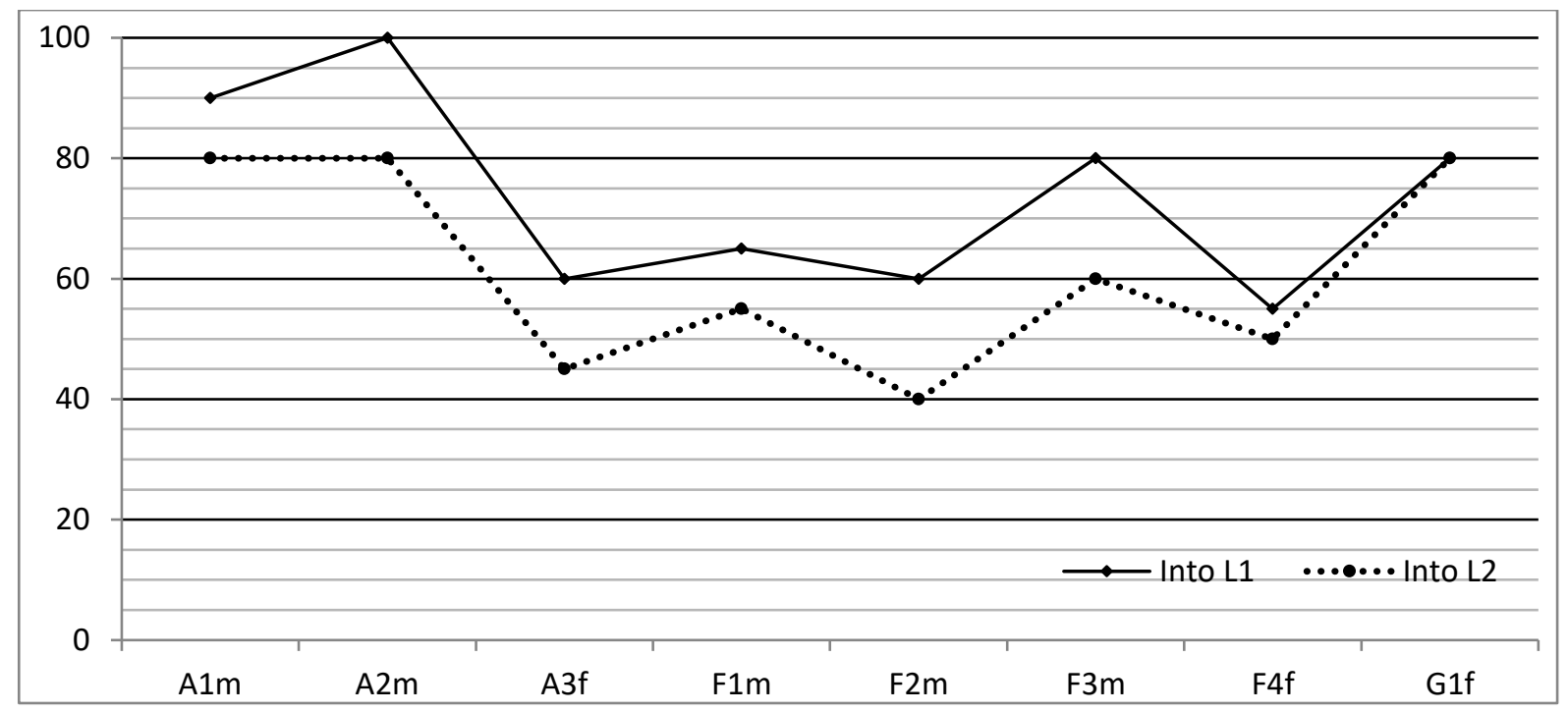

Figure 1: Effect of interpreting direction on language quality

\subsubsection{Content}

The findings regarding the content mark for the two different interpreting directions are less clear-cut. As illustrated in Figure 2, five interpreters achieved a higher content mark during first-language interpreting, two interpreters (F1m and F4f) were awarded a higher content mark for second-language interpreting, and one interpreter $(\mathrm{A} 2 \mathrm{~m})$ was awarded the same content mark for both interpreting directions. Although the majority of participants therefore perform better during first-language interpreting, three participants perform equally well or even better during second-language interpreting. In addition, the differences in marks between first- and second-language interpreting are relatively small, at only $5 \%$ in the case of A1m and F3m. In other cases, such as that of F2m, the difference is as large as $25 \%$. (The German interpreter's better performance during first-language interpreting may be attributed to the fact that the source speech in this direction contained a lower type/token ratio. However, the Afrikaans interpreters, for whom first-language interpreting presented a slower input rate, achieved mixed results; as did the French interpreters, for whom neither input rate nor type/token ratio can be considered confounding variables.) Figure 2 below presents the marks awarded to each individual participant for his or her first- and second-language renditions and reflects the mixed nature of the results. In line with the conflicting findings evident in the literature, some interpreters therefore produce better output during first-language interpreting, while others perform better or equally well during second-language interpreting. This conflicting finding is analysed in more detail in section 4.3 below. 


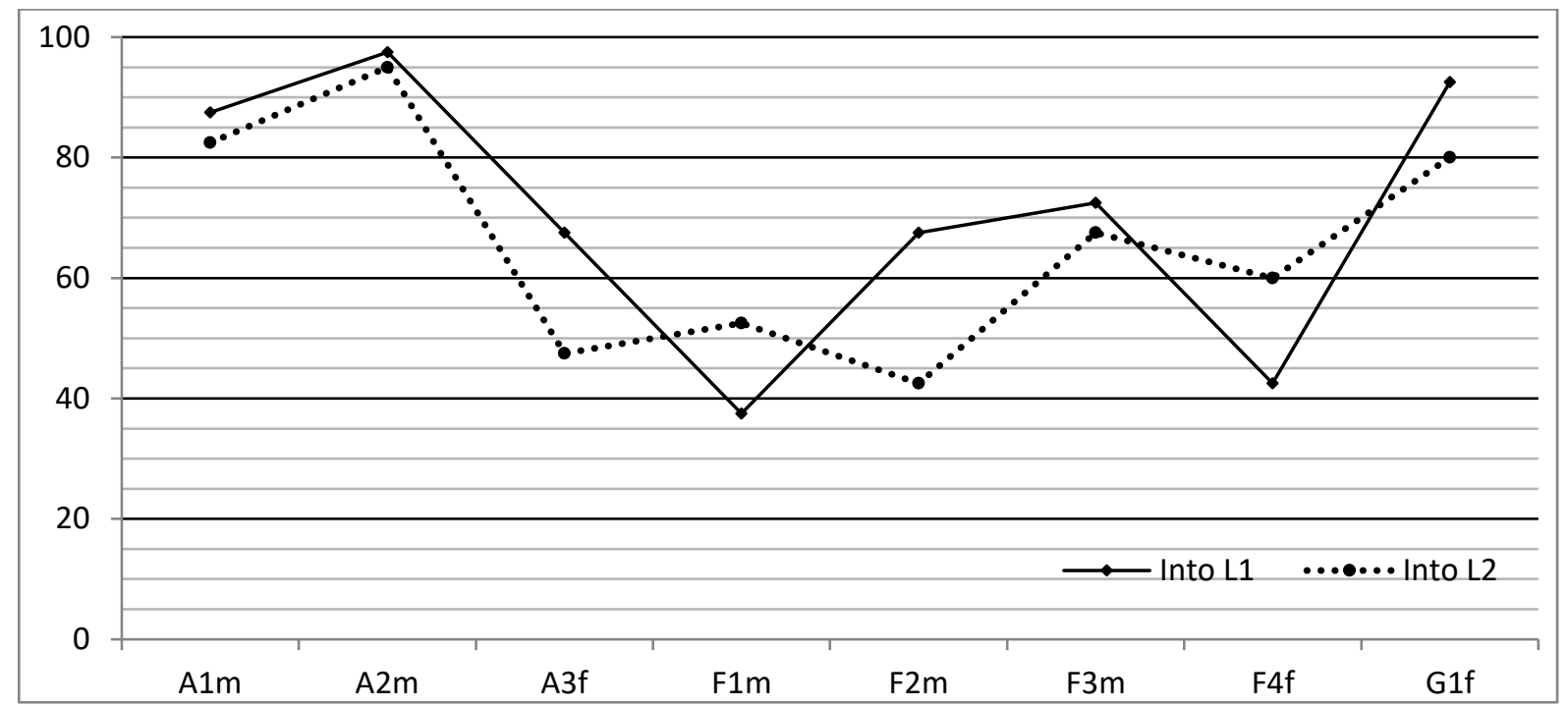

Figure 2: Effect of interpreting direction on content

\subsection{Topic familiarity}

\subsubsection{Language}

Comparing participants' language marks for the two familiar speeches (into interpreters' first and second languages) to their language marks for the two unfamiliar speeches (into interpreters' first and second languages) again yields conflicting results, which are illustrated in Figure 3 below. Three interpreters (F1m, F2m, and F4f) achieve a higher language mark for interpreting the familiar speeches; two interpreters (A1m and A3f) are awarded higher marks for interpreting the unfamiliar speeches; and three interpreters (A2m, F3m, and G1f) achieve the same mark regardless of their level of familiarity with the topic of the speech. Hence, there appears to be no consistent benefit of topic familiarity on the language quality of the output produced by the participants in this study according to the examiners' assessment. (Neither input rate nor type/token ratio constitute confounding variables as far as the familiar/unfamiliar comparison is concerned, as the familiar and unfamiliar source speeches are comparable in terms of input rate and type/token ratio.) 


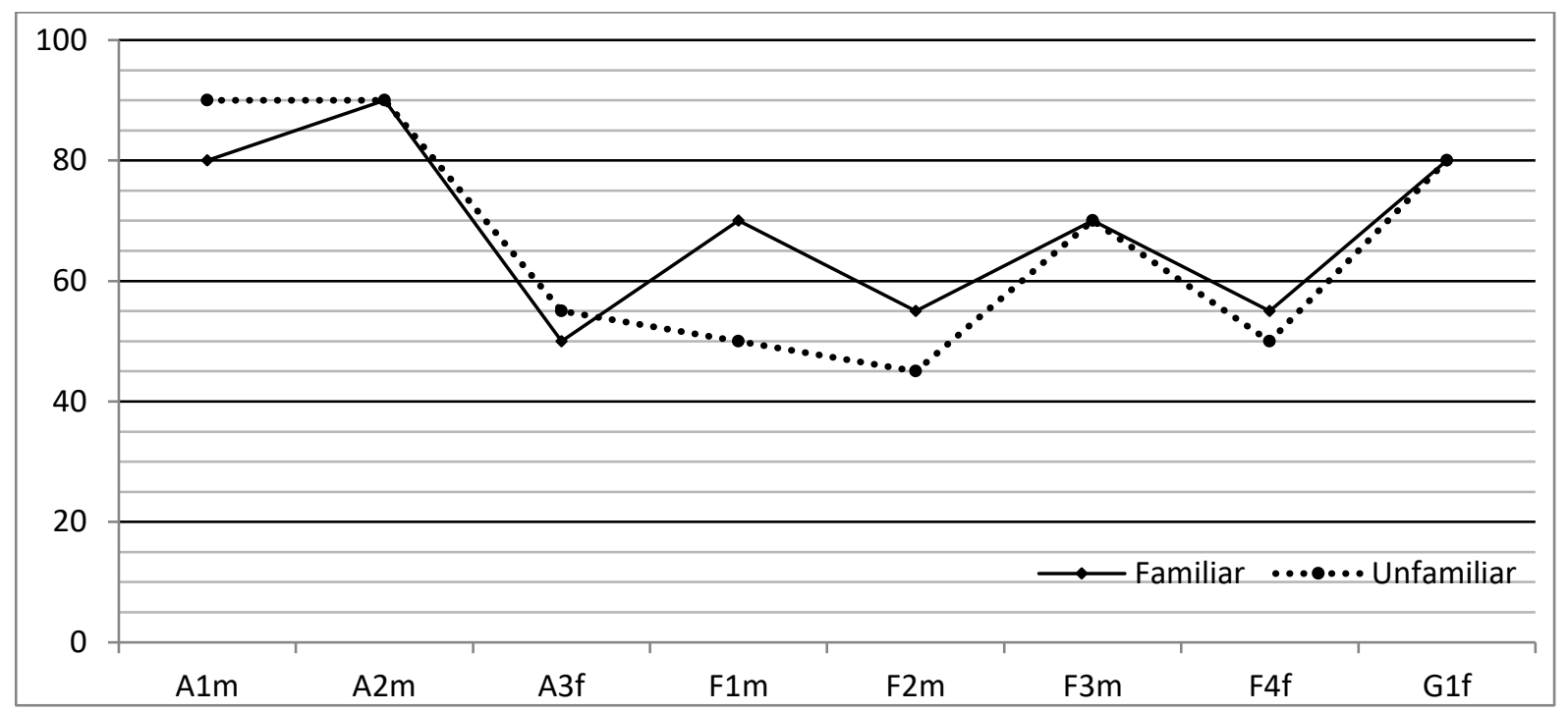

\section{Figure 3: Effect of topic familiarity on language quality}

\subsubsection{Content}

Results are equally inconsistent regarding the content marks awarded. Figure 4 shows that four interpreters (F1m, F2m, F3m, and F4f) achieve higher marks when familiar with the topics of the source speeches; one interpreter (G1f) achieves a higher mark when unfamiliar with the topic of the source speech; and three interpreters (A1m, A2m, and A3f) are awarded the same marks regardless of their degree of familiarity with the topics of the source speeches. Therefore, the findings regarding the content of the interpreters' output under different levels of context familiarity are as conflicting as those regarding language quality. (Neither input rate nor type/token ratio constitute confounding variables as far as the familiar/unfamiliar comparison is concerned, as the familiar and unfamiliar source speeches are comparable in terms of input rate and type/token ratio.)

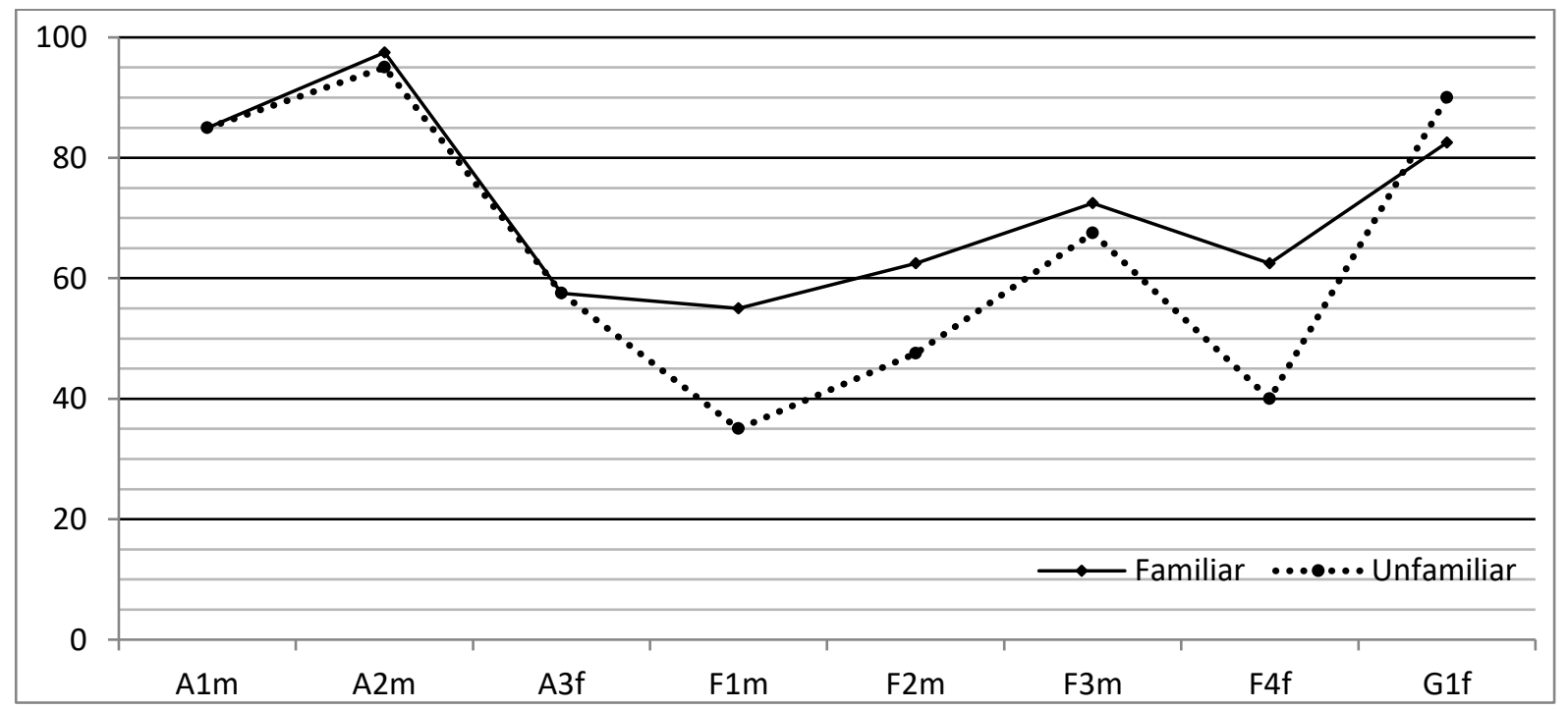

\section{Figure 4: Effect of topic familiarity on content}


It can be concluded that the linguistic quality of participants' output (assessed via the "Language" category on the rubric) appears to be affected by interpreting direction, with the majority of interpreters achieving higher quality during first-language interpreting. Topic familiarity, on the other hand, has no consistent effect on language quality. (It should be noted that, as these results are based on the marks awarded to students during their examination, the findings may have been biased by examiners' assumptions regarding the participants' native languages based on their accents and names.)

Results regarding the content of interpreters' output (assessed via the "Content" category on the rubric) are conflicting, as is existing literature on this issue (Tommola \& Helevä 1998; Tommola \& Laakso 1997; Chang 2005), and no consistent trend regarding the effects of either interpreting direction or topic familiarity can be identified. The content marks achieved by participants during the four individual interpreting situations are hence examined more closely below in order to determine to what extent topic familiarity may affect interpreter performance differently during first- and second-language interpreting and therefore possibly account for the conflicting findings in this as well as other studies on directionality.

\subsection{Interaction between topic familiarity and interpreting direction: Content}

If extralinguistic knowledge or context familiarity can compensate for linguistic gaps in comprehension, as argued by Gile (2009:83), then a higher level of familiarity would arguably impact positively on first-language interpreting, where comprehension takes place in a nonnative language. Setton (2004:15) in addition argues that an understanding of the context could also compensate for interpreters' gaps in second-language production proficiency. This would imply that second-language interpreting, during which production takes place in a non-native language, may also benefit from interpreters' context familiarity. If one of the two interpreting directions benefits more than the other from context familiarity, then this could explain why studies on directionality that do not control for this factor often produce conflicting results. The following sections examine whether familiarity with the topic had an interpreting directionspecific effect on the performance of the interpreters in this study.

\subsubsection{Topic familiarity during first-language interpreting}

The content marks indicate that in the case of first-language interpreting, four interpreters $(\mathrm{F} 1 \mathrm{~m}$, F2m, F3m, and F4f) are awarded higher content marks when they are familiar with the topic, whereas four interpreters (A1m, A2m, A3f, and G1f) achieve higher content marks for their renditions of speeches on unfamiliar topics. Figure 5 illustrates the effect of topic familiarity on first-language interpreting. The fact that the four interpreters who are awarded higher marks when familiar with the topic are French and the four interpreters who perform better when unfamiliar with the topic are Afrikaans and German may create the impression that the differences in performance are caused by differences between the source speeches. However, it must be emphasised that this is not the case, as all eight interpreters interpreted the same (English) source language speeches into their respective first languages. These English speeches are highly comparable in terms of input rate (101 words per minute for the familiar speech and 106 words per minute for the unfamiliar speech) and type/token ratio (43.2 for the familiar speech and 43.4 for the unfamiliar speech). Language-pair-specific factors, as argued by Al-Salman and Al-Khanji (2002) and Kurz and Färber (2003), may however have played a role. 
As some interpreters perform better when interpreting a familiar topic into their first language, and others perform better when interpreting an unfamiliar topic into their first language, there appears to be no consistent effect of topic familiarity on the content of the interpreters' output during first-language interpreting.

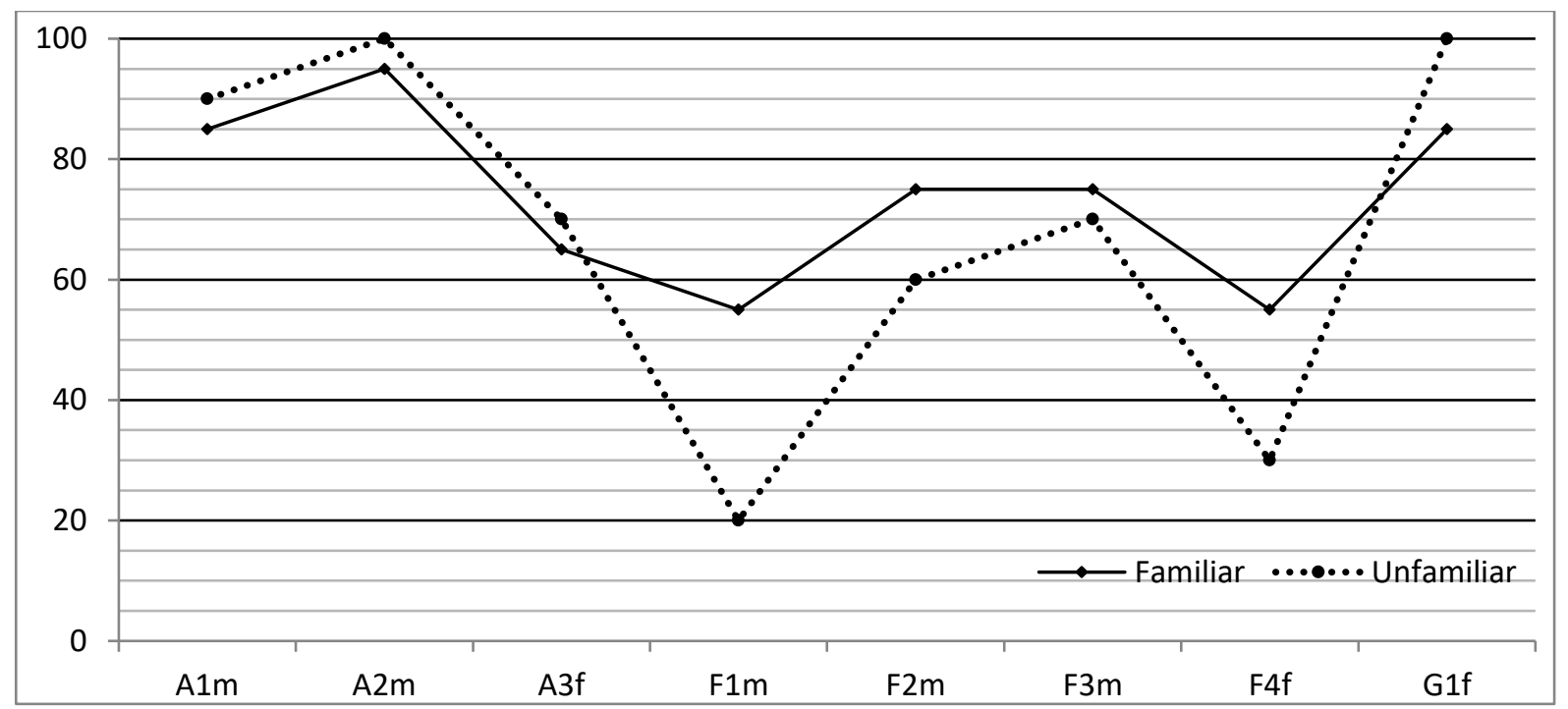

Figure 5: Effect of topic familiarity on content during first-language interpreting

\subsubsection{Topic familiarity during second-language interpreting}

During second-language interpreting, on the other hand, seven interpreters achieve higher content marks for their renditions of the familiar speeches, and only one interpreter (G1f) receives the same content mark for the speeches dealing with the familiar and unfamiliar topics. This finding, illustrated in Figure 6, suggests that, although interpreters' level of familiarity with the topics of the source speeches does not consistently affect their performance during first-language interpreting (section 4.3.1), it may have an effect on their performance during second-language interpreting. Note that as the sets of familiar and unfamiliar source speeches are comparable in terms of input rate and type/token ratio, these variables cannot be considered responsible for these results. 


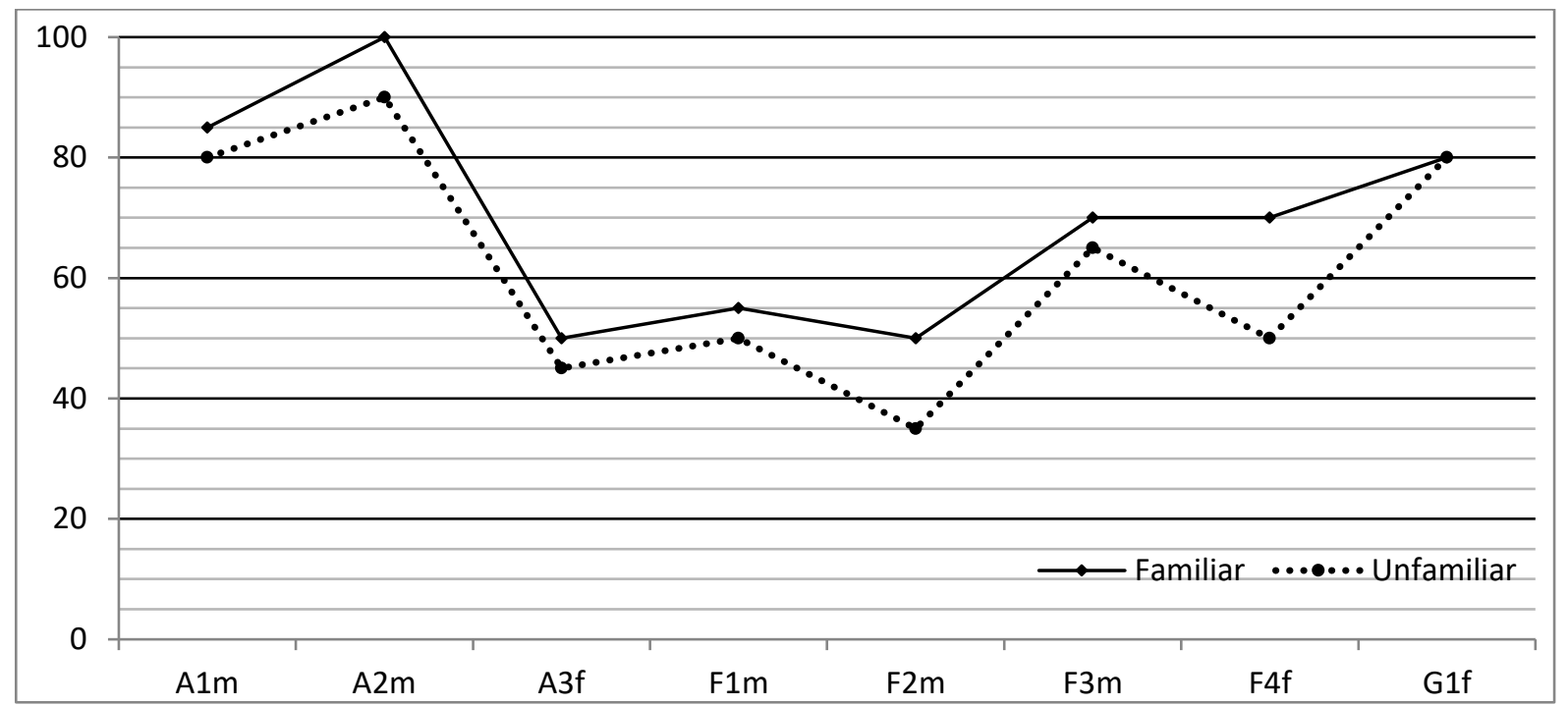

Figure 6: Effect of topic familiarity on content during second-language interpreting

\subsection{Discussion}

The above finding suggests that familiarity with the topic of the speech to be interpreted is more relevant for an interpreter working into a non-native language than it is during first-language interpreting, at least as far as the content of the message is concerned. Therefore, although the linguistic quality of participants' output is higher during first-language interpreting, interpreting direction cannot serve as the main indicator of interpreting performance in terms of the content of the target language output. It emerges that interpreting direction cannot be considered in isolation. Instead, it appears that topic familiarity is more likely to be beneficial for interpreters working into their second language, but has a less consistent effect on first-language interpreting.

One plausible explanation for this finding is Setton's (2004) suggestion that topic familiarity may compensate for linguistic gaps at the level of non-native target language production. It is possible that participants in this study already comprehend input in their non-native and native languages equally well, but that differences exist between native and non-native production in the two different interpreting directions. This may be the reason that interpreters' topic familiarity has more of a compensatory effect on non-native production proficiency during second-language interpreting than on non-native comprehension during first-language interpreting. Godjins and Fabbro (2002) support the notion that problems in interpreting are more likely to occur in non-native production than in non-native comprehension. This may explain why the positive effect of topic familiarity may be more noticeable during secondlanguage interpreting.

The above idea that context familiarity compensates more for shortcomings in second language speech production during second-language interpreting than it compensates for shortcomings in second language comprehension during first-language interpreting may also support the notion that, in simultaneous interpreting, target speech production requires more processing capacity than source speech comprehension (Gile 2005). The benefits of topic familiarity would therefore be more noticeable at this level, which may be why less consistent benefits are 
obtained by compensating for the (presumably inferior) second-language comprehension capacity during first-language interpreting than by compensating for the (presumably inferior) second-language production capacity during second-language interpreting. Gile (2005) argues that second-language interpreting may be considered more demanding in terms of processing capacity if one assumes that the production effort requires more capacity than the listening effort, and that both comprehension and production require more processing capacity in a second than in a first language. As second-language interpreting benefits most from topic familiarity, and assuming that this is due to the fact that topic familiarity compensates for the gaps in the interpreter's non-native production, this may indicate that production does indeed take up more processing capacity than listening in simultaneous interpreting.

Another conceivable explanation for the finding that topic familiarity holds greater benefits for second- than for first-language interpreting is the possibility that during second-language interpreting, interpreters allocate such a large proportion of their processing capacity to nonnative production that only a comparatively small amount of processing capacity remains available for comprehension. This creates a native source language comprehension gap, which can consequently be compensated for by interpreters' topic familiarity. Gile (1993) makes a similar argument, suggesting that an interpreter with greater increased extralinguistic knowledge may need less knowledge of the language to achieve comprehension. Gumul (2006: slide no. 25) finds that interpreters explicitate more during second-language interpreting; and suggests along similar lines that during this interpreting direction, interpreters allocate all available processing capacity to the production effort. This necessitates the more frequent use of interpreting strategies such as parallel reformulation in order to overcome source speech comprehension gaps. During first-language interpreting, on the other hand, less processing capacity is required for target-language production (which takes place in the interpreter's first language), meaning that more capacity remains available for comprehension, which then needs to rely to a lesser extent on topic familiarity.

Lastly, it must be pointed out that the amounts of processing capacity required for source speech comprehension and for target language production may in fact be dynamic and differ from interpreter to interpreter or be affected by various other factors such as the source language speaker and the language pair (Gile 2005). The precise cognitive processes that lead to the above interpreting performances are therefore difficult to establish. However, the results of the present study suggest that interpreting direction should not be considered in isolation. Other variables may have an effect on interpreters' performance in different interpreting directions and may interact differently with one interpreting direction than with another.

\section{Conclusion}

In conclusion, as far as the content of the target language message is concerned, interpreting direction per se appears not to be the main predictor of interpreter performance based on the examiners' assessments. Language quality, on the other hand, is higher during first-language interpreting than during second-language interpreting and is therefore affected by interpreting direction. Increased linguistic quality during first-language interpreting is consistent with the findings of other studies, such as Chang (2005) and Darò et al. (1996). The preference traditionally given to first-language interpreting therefore seems valid only as far as the linguistic quality of the interpreter's output is concerned. Even though professional interpreters tend to consider linguistic quality to be important, focusing on aspects such as correct 
grammatical usage, the users of interpreting services have been shown to attach much less value to this feature of the interpreted message (Kurz 1993). The preference given to first-language interpreting hence does not appear justified in terms of the content of the interpreters' output. Regarding linguistic quality, the advantages of first-language interpreting can be considered of minor relevance as far as users' quality perceptions are concerned.

The present small-scale study suggests that the content accuracy of the target-language rendition may not be affected consistently by interpreting direction or by topic familiarity per se. Instead, it may benefit from topic familiarity (obtained in this case through topic-specific interpreter training) during second-language interpreting in particular. Topic familiarity appears to provide more consistent benefits during second- than during first-language interpreting. The present findings therefore provide support for Donovan's (2004) suggestion that an interpreter's background knowledge could be more important during second- than during first-language interpreting. The above findings may also provide an explanation for the inconsistency in the literature regarding the effect of interpreting direction on the content of interpreters' output (discussed in section 2.1). The fact that content has been found by various scholars to be superior during second-language interpreting (Tommola \& Helevä 1998), during first-language interpreting (Chang 2005), or to be unaffected by interpreting direction (Tommola \& Laakso 1997) could be the result of the fact that topic familiarity (or possibly other extralinguistic factors) in these studies has interacted with interpreting direction to affect the success with which the content of the source speech is transferred into the target language.

As the results of the present pilot study suggest that there may be a possible interaction between interpreting direction and interpreters' familiarity with the topic of the speech to be interpreted, more studies using larger samples of interpreters need to be carried out in order to confirm these initial findings. Future studies should carefully control for source speech variables such as input rate, type/token ratio, and lexical density in order to preclude any confounding effect of these variables. They may possibly also measure interpreter performance using instruments other than the possibly somewhat subjective assessment process. The interaction between interpreting direction and other extralinguistic variables that have been suggested to be relevant to the issue of interpreting direction, such as interpreters' level of expertise, language pair-specific factors, or the degree of technicality of the source speech, should also be investigated. Once more information regarding the interaction of interpreting direction with other extralinguistic factors is available, more accurate statements regarding the superiority of any one interpreting direction can be made.

\section{References}

Al-Salman, S. and R. Al-Khanji. 2002. The native language factor in simultaneous interpretation in an Arabic/English context. Meta 47(4): 607-626. doi:10.7202/008040ar

Barik, H. C. 1994. A description of various types of omissions, additions and errors of translation encountered in simultaneous interpretation. In S. Lambert and B. Moser-Mercer (eds.), Bridging the Gap: Empirical Research in Simultaneous Interpretation. Amsterdam and Philadelphia: John Benjamins. doi:10.1075/btl.3.12bar 
Bartłomiejczyk, M. 2004. Simultaneous interpreting A-B vs. B-A from the interpreters' standpoint. In D. Gile, G. Hansen and K. Malmkjær (eds.), Claims, Changes and Challenges in Translation Studies: Selected Contributions from the EST Congress, Copenhagen 2001. Amsterdam and Philadelphia: John Benjamins. pp. 239-249. doi:10.1075/btl.50.20bar

Bartłomiejczyk, M. 2006. Strategies of simultaneous interpreting and directionality. Interpreting 8(2): 149-174. doi:10.1075/intp.8.2.03bar

Chang, C. 2005. Directionality in Chinese/English SI: Impact on Performance and Strategy Use. Doctoral dissertation. Austin: University of Texas at Austin.

Darò, V., S. Lambert and F. Fabbro. 1996. Conscious monitoring of attention during simultaneous interpretation. Interpreting 1(1): 101-124. doi:10.1075/intp.1.1.06dar

Denissenko, E. 1989. Communicative and interpretative linguistics. In L. Gran and J. Dodds (eds.), The Theoretical and Practical Aspects of Teaching Conference Interpretation. Udine: Campanotto. pp. 155-157.

Directorate General for Interpretation, European Commission. What is retour? Available online: http://ec.europa.eu/dgs/scic/what-is-conference-interpreting/retour/index_en.htm (Accessed 10 October 2014).

Donovan, C. 2002. Survey of users' expectations and needs. Teaching Simultaneous Interpretation into $a \quad B$ Language, Vol $I$ : 2-11. Available online: http://www.emcinterpreting.org/?q=taxonomy/term/31 (Accessed 28 September 2017).

Donovan, C. 2004. European Masters Project Group: Teaching simultaneous interpretation into a B language. Preliminary findings. Interpreting 6 (2): 205-216. doi:10.1075/intp.6.2.06don

Dose, S. 2014. Putting directionality into context. Stellenbosch Papers in Linguistics Plus 45: 71-88. doi:10.5842/45-0-625

Gile, D. 1990. L'évaluation de la qualité de l'interprétation par les délègués: Une étude de cas. The Interpreter's Newsletter 3: 66-71.

Gile, D. 1993. Translation/interpretation and knowledge. In Y. Gambier and J. Tommola (eds.), Translation and Knowledge. SSOTT IV: Scandinavian Symposium on Translation Theory, Turku. Turku: University of Turku.

Gile, D. 2005. Directionality in conference interpreting: A cognitive view. In R. Godijns and M. Hinderdael (eds.), Directionality in Interpreting: The "Retour" or the Native? Ghent: Communication and Cognition. pp. 9-26.

Gile, D. 2009. Basic Concepts and Models for Interpreter and Translator Training. Amsterdam and Philadelphia: John Benjamins. 
Godjins, R. M. and F. Fabbro. 2002. The role of working memory in oral translation: Experience based on the token test. In G. Garzone, P. Mead and M. Viezzi (eds.), Perspectives on Interpreting. Bologna: Cooperativa Libraria Universitaria Editrice Bologna. pp. 79-90.

Gumul, E. 2006. Explicitation and Directionality in Simultaneous Interpreting. Available online:

$\mathrm{http} / /$ www.google.co.uk/url?sa=t\&rct=j\&q=Explicitation+\%26+directionality+in+simultaneo us+interpreting \&source $=$ web $\& \mathrm{~cd}=1 \&$ ved $=0 \mathrm{CCcQFjAA} \& u r l=h t t p \% 3 \mathrm{~A} \% 2 \mathrm{~F} \% 2 \mathrm{Fwww} \cdot \mathrm{emcint}$ erpreting.org\%2Frepository\%2Fppt $\% 2$ FUoW_conf_06-

E.Gumul.ppt\&ei=HT82T67kPO3vmAWhhO33AQ\&usg=AFQjCNHL1xqF_AUNPtD5mMe9 AktLHgikYg. (Accessed 11 February 2012).

Harris, B. 1989. Norms in interpretation. Target 2(1): 115-119. doi:10.1075/target.2.1.08har

Hyönä, J., J. Tommola and A. Alaja. 1995. Pupil dilation as a measure of processing load in simultaneous interpreting and other language tasks. The Quarterly Journal of Experimental Psychology 48(A): 598-612. doi:10.1080/14640749508401407

Kalina, S. 2005. Quality in the interpreting process: What can be measured and how? In R. Godijns and M. Hinderdael (eds.), Directionality in Interpreting: The "Retour" or the Native? Ghent: Communication and Cognition. pp. 27-46.

Kurz, I. and B. Färber. 2003. Anticipation in German-English simultaneous interpreting. Forum 1(2): 123-150. doi:10.1075/forum.1.2.06kur

Kurz, I. 1993. Conference interpretation: Expectations by different user groups. The Interpreters' Newsletter 5: 13-21.

Kurz, I. 1994. A look into the 'black box' - EEG probability mapping during mental simultaneous interpreting. In M. Snell-Hornby, F. Pöchhacker and K. Kaindl (eds.), Translation Studies - An Interdiscipline. Amsterdam and Philadelphia: John Benjamins. pp. 199-208. $\underline{\text { doi:10.1075/btl.2.25kur }}$

Lim, H.O. 2005. Working into the B language: The condoned taboo? Meta: Translators' Journal 50(4): 1-19. doi:10.7202/019870ar

Marian, V., H.K. Blumenfeld and M. Kaushanskaya. 2007. The Language Experience and Proficiency Questionnaire (LEAP-Q): Assessing language profiles in bilinguals and multilinguals. Journal of Speech Language and Hearing Research 50(4): 940-967. doi:10.1044/1092-4388(2007/067)

Pavlovič, N. 2007. Directionality in translation and interpreting practice. Report on a questionnaire survey in Croatia. In A. Pym and A. Perekrestenko (eds.), Translation Research Projects 1. Tarragona: Intercultural Studies Group. pp. 79-95. 
Sandrelli, A. and C. Bendazzoli. 2015. Lexical patterns in simultaneous interpreting. A preliminary investigation of EPIC (European Parliament Interpreting Corpus). Available online:

http://webcache.googleusercontent.com/search?q=cache:_-

ahpH9Xv3MJ:www.birmingham.ac.uk/Documents/college-artslaw/corpus/conferencearchives/2005-

journal/ContrastiveCorpusLinguistics/lexicalpatternsinsimultaneousinterpreting. $d o c+\& c d=1 \&$ $\mathrm{hl}=\mathrm{en} \& \mathrm{ct}=\mathrm{clnk} \& \mathrm{gl}=\mathrm{za}$ (Accessed 27 September 2017).

Seleskovitch, D. 1978. Interpreting for International Conferences. Washington: Pen and Booth.

Setton, R. 2004. New demands on interpreting and the learning curve in interpreter training. International Interpreting Conference 2004 and Fifth National Conference on Interpreting Practice, SISU, Shanghai November 2004. pp. 1-20.

Tommola, J. and M. Helevä. 1998. Language direction and source text complexity: Effects on trainee performance in simultaneous interpreting. In L. Bowker, M. Cronin, D. Kenny and J. Pearson (eds.), Unity in Diversity? Current Trends in Translation Studies. Manchester: St. Jerome. pp. 177-186.

Tommola, J. and T. Laakso. 1997. Source-text segmentation, speech rate and language direction: Effects on trainee SI. In K. Klaudy and J. Kohn (eds.), Transferre Necesse Est. Proceedings of the Second International Conference on Current Trends in Studies of Translation and Interpreting. Budapest: Scholastica. pp. 186-191.

Viaggio, S. 1991. Cognitive closing to teach them to think. The Interpreter's Newsletter 4: 4044.

Vuorikoski, A. R. 2004. A Voice of its Citizens or a Modern Tower of Babel? Doctoral dissertation. Tampere: University of Tampere. Available online: http://tampub.uta.fi/handle/10024/67348 (Accessed 3 August 2013). 